\title{
Células-tronco mesenquimais
}

\author{
Mesenchymal stem cell \\ Betânia Souza Monteiro ${ }^{\text {I* }}$ Napoleão Martins Argolo NetoII \\ Ricardo Junqueira Del Carlo ${ }^{I I I}$
}

\section{RESUMO}

Dentre todas as células-tronco estudadas até o presente momento, as mesenquimais (MSC) destacam-se por sua elevada plasticidade, podendo originar tecidos mesodermais e não mesodermais. Além disso, possuem características imunomoduladoras e imunossupressoras que ampliam as possibilidades de utilização terapêutica. As MSC secretam uma grande variedade de citocinas pró e antiinflamatórias e fatores de crescimento e, por meio dessas moléculas bioativas, proporcionam a modulação da resposta inflamatória, o restabelecimento do suprimento vascular e a reparação adequada do tecido, contribuindo para a homeostasia tissular e imunológica sob condições fisiológicas. Também podem induzir as demais células presentes no nicho tecidual a secretarem outros fatores solúveis que estimulam a diferenciação dessas células indiferenciadas, favorecendo o processo de reparação. A terapia celular com MSC é uma alternativa terapêutica promissora, porém a compreensão da biologia dessas células ainda é uma ciência em formação. Este artigo tem por objetivo realizar uma breve revisão sobre as células mesenquimais indiferenciadas.

Palavras-chave: terapia celular, propriedades imunológicas, fatores solúveis, citocinas, reparação tecidual.

\section{ABSTRACT}

Of all the stem cells studied so far, the mesenchymal stem cells (MSC) stand out for their high plasticity and capacity of generating mesodermal and non-mesodermal tissues. In addition, immunomodulatory and immunosuppressive features that expand possibilities for therapeutic use are present in these cells. A variety of pro and anti-inflammatory cytokines and growth factors are secrete for MSC and provide a modulation of inflammatory response, re-establishment of vascular supply and adequate repair of the tissue, contributing to tissue homeostasis under physiologic conditions. Therefore, they can induce secretion of soluble factors that stimulate their differentiation by other cells present at the niche's tissue, promoting the repair process. Cell therapy using MSC is a promises therapeutic alternative, but understanding the biology of these cells is still under construction. The aim of the article is to conduct a short review of these undifferentiated mesenchymal cells.

Key words: cell therapy, immunological properties, growth factors, cytokines, tissue repair.

\section{INTRODUÇÃO}

As células-tronco mesenquimais (MSC) são consideradas uma linhagem de células-tronco somáticas e estão presentes em regiões perivasculares de todos os tecidos adultos, em pequenas quantidades, incluindo a medula óssea (MO), o tecido adiposo, o periósteo, o tecido muscular e os órgãos parenquimatosos (MEIRELLES et al., 2008; MAMBELLI et al., 2009; ZUCCONI et al., 2009). AMO constitui um dos principais sítios doadores dessas células, assim como de células-tronco hematopoéticas e endoteliais (PITTENGER et al., 1999; MINGUELL et al., 2000).

'Programa de Pós-graduação em Medicina Veterinária, Universidade Federal Viçosa (UFV), 36570-000, Viçosa, MG, Brasil. E-mail: betaniamonteiro@hotmail.com.*Autor para correspondência.

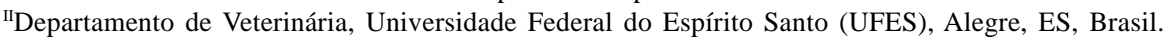

IIIDepartamento de Veterinária, UFV, Viçosa, MG, Brasil. 
As MSC caracterizam-se por ser uma população de células multipotentes capazes de se diferenciar e produzir qualquer tipo celular necessário num processo de reparação, como osteoblastos, condroblastos, hepatócitos, neurônios, células epiteliais, renais, cardíacas, dentre outras (PITTENGER et al., 1999). Tais características de plasticidade sugerem que esse tipo celular é o responsável pelo turnover e pela manutenção de todos os tecidos do organismo (CAPLAN, 2009). Elas tornaram-se foco de inúmeras pesquisas em todo o mundo por fornecer perspectivas clínicas promissoras para a terapia celular.

Em culturas e em condições adequadas de cultivo, as MSC exibem morfologia fibroblastoide, adesão em substrato plástico, autorrenovação e diferenciação em tipos celulares distintos (MENDELOW et al., 1980; PITTENGER et al., 1999; NARDI \& MEIRELLES, 2006). Podem ser expandidas por mais de 40 gerações mantendo capacidade multipotente, embora reduzam as taxas de mitose e haja uma grande probabilidade de acúmulo de mutações, tornando desaconselhável seu uso clínico, nestas condições (DEANS \& MOSELEY, 2000).

As MSC expressam um grande número de moléculas bioativas como as moléculas de adesão, as proteínas de matriz extracelular, as citocinas e os receptores para fatores de crescimento, permitindo interações com demais células (HUSS, 2000; BOBIS et al., 2006). Essas moléculas atuam modulando a resposta inflamatória, angiogênese e mitose das células envolvidas no processo de reparação tecidual (WAN et al., 2008; CAPLAN, 2009).

\section{Plasticidade das MSC}

De todas as linhagens de células-tronco somáticas estudadas até o presente momento, as MSC apresentam maior plasticidade, originando tecidos mesodermais e não mesodermais (MEIRELLES et al., 2006). Contudo, os mecanismos de plasticidade não são totalmente compreendidos.

Inicialmente acreditava-se que as MSC originavam linhagens celulares diferentes por transdiferenciação. Segundo essa teoria, elas alterariam sua expressão gênica para a de uma linhagem celular completamente diferente, originando tipos celulares distintos (HERZOG et al., 2003). A transdiferenciação pode ocorrer de forma direta, quando a célula altera seu citoesqueleto e sua síntese protéica para rediferenciar-se em outro tipo celular específico, ou indireta, quando desdiferencia-se em uma célula-tronco mais primitiva para, posteriormente, se rediferenciar em outro tipo celular (VERFAILLIE, 2002; HERZOG et al., 2003).
Outro mecanismo de diferenciação celular proposto é a fusão. Acredita-se que as MSC podem fusionar-se a uma célula adulta-alvo, assumindo o padrão de expressão gênica da célula adulta a qual se uniu. A fusão celular é um fenômeno biológico amplamente conhecido, ocorrendo principalmente nas células cuja poliploidia (dois ou mais conjuntos de cromossomos) é comumente vista, como em hepatócitos e células musculares esqueléticas (HERZOG et al., 2003; MEIRELLES et al., 2006).

Além disso, as MSC secretam uma grande variedade de quimiocinas, além de expressar receptores para citocinas e fatores de crescimento. Dessa forma, as MSC interagem com as células residentes (nicho) e podem induzi-las, por mecanismo parácrino, a se diferenciar em linhagens celulares distintas, de acordo com essa sinalização (TAKAHASHI et al., 2007).

\section{Pericitos e MSC}

Os pericitos são células presentes na parede vascular de arteríolas pré-capilares e nas pequenas artérias e veias (HIRSCHI \& D’AMORE, 1996; MEIRELLES et al., 2008). São conhecidas também como células periendoteliais, célula reticular adventicial ou células de Rouget, as quais estão embebidas na membrana basal, onde entram em contato com o endotélio vascular e as células endoteliais (HIRSCHI \&D'AMORE, 1996;ARMULIKetal., 2005; MEIRELLES et al., 2008).

Alguns estudos evidenciaram que os pericitos são células multipotentes com capacidade de se diferenciar em condrócitos, adipócitos e osteoblastos, fato que explica, por exemplo, a calcificação patológica dos vasos sanguíneos, as válvulas cardíacas e o músculo esquelético (HIRSCHI \& D’AMORE, 1996; MEIRELLES et al., 2008). Ademais, recentes pesquisas demonstram que existem semelhanças entre os marcadores de superfície expressos pelas MSC e pelos pericitos (CAPLAN, 2008) e que os pericitos são as células que, in vivo, mais se assemelham e correspondem às culturas de MSC (MEIRELLES et al., 2006; CAPLAN, 2008; MEIRELLES et al., 2008). Por essas evidências, definiu-se que todas as MSC são pericitos, mas nem todas as células que estão localizadas na região perivascular são MSC, como, por exemplo, as células-tronco neural e hematopoética (HIRSCHI \& D’AMORE, 1996; CAPLAN, 2008).

\section{Imunifenotipagem}

Todas as células do organismo apresentam um conjunto de marcadores de superfície que caracterizam a singularidade biológica e a marca das 
células que os contêm (COVAS, 2006). Contudo, as MSC apresentam poucos marcadores imunofenotípicos específicos (ALHADLAQ \& MAO, 2004; MEIRELLES et al., 2006), sendo sua caracterização estabelecida pela identificação de um perfil de marcadores específicos e não específicos. Essa imunofenotipagem é realizada com a utilização de anticorpos monoclonais que reconhecem esses antígenos de superfície da membrana celular, conforme demonstrado em estudos contemporâneos (MEIRELLES et al., 2006; LOJUDICE, 2008).

A população de MSC isoladas da medula óssea de humanos e camundongos expressa em sua superfície marcadores moleculares como: CD44 (receptor de hialuronato), CD105 (endoglina: marcador angiogênico), CD106 (VCAM-1: molécula de adesão vascular), CD166 (ALCAM: moléculas de adesão de leucócitos ativados), CD29 (integrinas VLA-ß), CD73 (SH3 e SH4), CD90 (Thy-1), Stro-1(estroma de suporte da hematopoese) e Sca-1 (GRONTHOS et al., 2003; KOLF et al., 2007; PHINNEY \& PROCKOP, 2007). KOLF et al. (2007) afirmaram que o marcador Stro-1 é o melhor marcador a se investigar quando se deseja pesquisar a presença de MSC. Entretanto, esse marcador é gradualmente perdido durante a expansão em culturas.

Paralelamente, existe um consenso na literatura de que as MSC não possuem marcadores típicos de células de linhagens hematopoéticas e endoteliais, como, por expemplo: CD11b (marcador de célula imune - integrina Mac-1), CD14 (receptor de lipopolissacarídeo LPS), CD31 (PECAM-1: molécula de adesão plaquetária), CD33 (receptor transmembrana de células mieloides), CD34 (receptor de células endoteliais), CD133 e CD45 (presentes em todas as células hematopoéticas). A ausência dos antígenos CD14, CD34 e CD45 na superfície dessas células mesenquimais permite distingui-las das precursoras hematopoéticas (KOLF et al., 2007).

Embora já tenham sido identificados oito marcadores de superfície para identificação de MSC, a International Society for Cellular Therapy concorda que apenas a identificação dos marcadores CD105, CD73 e CD90, quando não estiverem expressos marcadores hematopoéticos, é suficiente para a imunofenotipagem dessas células. Contudo, essa caracterização deve sempre estar acompanhada da demonstração da aderência celular por longos períodos em cultura e da diferenciação destas em pelo menos duas linhagens celulares distintas (HORWITZ et al., 2005).
Propriedades Imunológicas

As MSC tornaram-se foco de atenção terapêutica em razão de seu potencial imunomodulatório (WAN et al., 2008), embora os mecanismos de imunossupressão sobre a resposta inflamatória e sobre os mecanismos de rejeição ao transplante não estejam totalmente elucidados (PATEL et al., 2008).

Mediante um contato direto das MSC com um tecido (alogênico ou autólogo) ou mediante a interação parácrima com o interferon-gama (INF- $\gamma$ ), produzido pelas células imune do organismo, as MSC desencadeiam a liberação de diversos fatores solúveis que atuarão sobre as células do sistema imunológico (linfócitos e células dendríticas apresentadoras de antígeno - APC) (CORCIONE et al., 2006; NAUTA \& FIBBE, 2007). Dentre esses fatores, estão as prostaglandinas (PGE2), as interleucinas (IL-4, IL-6, IL10), o fator de crescimento transformador beta (TGF$ß)$, o fator de crescimento hepatoide (HGF) e a enzima indoleamine 2,3-dioxygenase (IDO) (NAUTA \& FIBBE, 2007).

A liberação de TGF-ß e HGF suprime a proliferação dos linfócitos T e B (Di NICOLA et al., 2002), enquanto que a liberação de PGE2 inibe, especificamente, a produção dos linfócitos $\mathrm{T}$ citotóxicos e as demais citocinas pró-inflamatórias. A enzima IDO induz a apoptose dos linfócitos $\mathrm{T}$ por transformar o triptofano, que é um aminoácido essencial para a ativação dessas células em produtos tóxicos no seu citoplama (AGGARWAL \& PITTENGER, 2005). De forma análoga aos mecanismos anteriormente descritos, a IDO, PGE2 e TGF-ß induzem a perda do potencial citotóxico das células natural killer (NK), por suprimirem a produção de IL-2, IL-15 e INF- $\gamma($ SOTIROPOULOU et al., 2006).

Em relação às APC, evidenciou-se que as MSCs interferem na diferenciação, maturação e ativação dessas células por meio da produção de IL-6 e de fator de crescimento estimulador de macrófago (M-CSF). Além disso, a liberação de PGE2 pelas MSCs inibe a produção e secreção de fator de necrose tumoral alfa (TNF-a) e de INF-r e estimula a produção de citocina anti-inflamatória IL-10 (AGGARWAL \& PITTENGER, 2005; NAUTA\& FIBBE, 2007).

Além dos efeitos imunossupressores, as MSC expressam pequenas quantidades de complexo de histocompatibilidade principal (MHC-I) e níveis negligenciáveis de MHC-II (Le BLANC, 2003) e/ou não expressão MHC-II em sua superfície (CAPLAN, 2009). Durante o processo de seleção clonal positiva e negativa realizado pelas células de defesa do organismo (reconhecimento do próprio e do não próprio), essas 
células utilizam o MHC para realizar tal seleção. Logo, na ausência de MHC, como verificado nas MSC, o processo de seleção de não próprio não ocorre, impedindo que o organismo que recebeu essas células indiferenciadas as reconheçam como não próprias e realize a rejeição destas (WAN et al., 2008; MAJUMDAR et al., 2003).

Também o contato célula-célula faz com que haja a produção, pelas MSC, de diferentes tipos de fatores de crescimento solúveis, incluindo fator estimulador de colônias de granulócitos (G-CSF), fator estimulador de colônias de macrófagos e granulócitos (GM-CSF) e MCSF e diversas interleucinas (IL-1,6,7,8,11,12,14,15), que influenciam fibroblastos e células granulocíticas envolvidas no processo de inflamação (DEANS \& MOSELEY, 2000; BOBIS et al., 2006).

\section{A função da MSC na reparação dos tecidos}

A lesão tecidual ocasionada por traumas ou agentes químicos e/ou infecciosos pode resultar em perda anatômica e funcional da integridade dos tecidos. Imediatamente, uma sequência complexa de eventos é desencadeada na tentativa de restaurar a integridade da área lesada (MARTIN, 1997).

Após a lesão tecidual, um coágulo se forma logo nos primeiros minutos; as plaquetas tornam-se ativadas e liberam fatores de crescimento. Em sequência, desenvolve-se um processo inflamatório envolvendo as células do sistema imune (poucas horas após a lesão), primeiramente neutrófilos, macrófagos e células dendríticas (resposta imune inata) e, posteriormente, linfócitos (resposta imune adquirida) (MARTIN, 1997; TSIROGIANNI et al., 2006). Os macrófagos, além de iniciarem a resposta inflamatória, fagocitam os debris celulares, e substâncias antigênicas interagem com as células da resposta adaptativa e produzem moléculas estimulatórias e mediadores inflamatórios, que, inicialmente, ativam mecanismos e células participantes do processo de reparação (TSIROGIANNI et al., 2006).

Paralelamente à ocorrência da resposta inflamatória, as células endoteliais são ativadas pela lesão vascular e hipóxia tecidual, e mais células do sistema imune são quimioatraídas. Essa quebra na homeostasia tecidual gera um estímulo para a ativação do pericito/MSC. Em resposta a essa ativação e à perda de contato com as células endotelias e com a membrana basal, as células pericito/MSC proliferam-se, elevam o número de moléculas bioativas secretadas (fatores de crescimentos e moléculas de adesão, principalmente), migram para o local de lesão e/ou por diapedese entram na corrente circulatória onde exercerão efeitos parácrinos (TSIROGIANNI et al., 2006; MEIRELLES et al., 2008).
As MSC também expressam uma grande variedade de receptores para quimiocinas e fatores de crescimento. Dessa forma, as MSC podem ser estimuladas pelas células residentes (nicho) a se diferenciar ou secretar fatores solúveis que estimularão outros nichos celulares. Dessa forma, quanto mais agudo o processo patológico ou quanto mais vascularizada a região afetada, mais intensa é a sinalização do nicho e mais efetiva será a resposta das MSC (FUCHS et al., 2004; MORRISON et al., 2008).

As moléculas bioativas secretadas pelas MSC exercem efeitos tróficos no tecido adjacente, acarretando: (a) efeitos antiapoptóticos nas células tecido-específico, (b) efeitos imunomodulatórios sobre as células do sistema imune, (c) aumento da angiogênense, e (d) quimiotaxia para outras células jovens comprometidas com o processo de reparação (MEIRELLES et al., 2008). Assim, pode ocorrer redução da resposta inflamatória inicial, em algumas doenças isquêmicas, restabelecimento do suprimento vascular e reparação adequada do tecido, dependendo da extensão e gravidade dos danos tissulares.

\section{Terapia utilizando MSC em Medicina Veterinária}

O número de pesquisas visando a terapias reparativas utilizando células-tronco tem aumentado consideravelmente nos últimos anos, no Brasil e no mundo. Os resultados já estabelecidos e as possibilidades de sucesso estão gerando grandes expectativas entre a comunidade científica e a população leiga (Del CARLO et al., 2009). Estudos contemporâneos vêm sendo realizados, descrevendo a utilização alógena e autógena das MSC para a reparação de diversos tecidos. A grande aplicação em Medicina Veterinária deve-se também à geração de modelos experimentais aplicáveis em paciente humanos.

MONTEIRO et al. (2008) destacaram que a forma inócua de coleta de MSC favorece o uso autógeno desse tipo celular; contudo, a possibilidade de tratamento alógeno que vem sendo testada recentemente implica ampliação das perspectivas terapêuticas com essas células. Assim, pacientes em estados mórbidos desfavoráveis não precisariam submeter-se à coleta das MSC e reduzir-se-ia a espera do paciente pelo tratamento, uma vez que a cultura de MSC já estaria estabelecida.

Para as aplicações terapêuticas, utiliza-se desde a fração celular mononuclear da medula óssea (FCMMO), que contém pequenas quantidades de MSC, até culturas expandidas em laboratório, obtidas de diversos órgãos. As culturas de MSC podem ser aplicadas in situ (no local da lesão), isoladas ou combinadas com substitutos ósseos e biomateriais ou 
infusão intravenosa (MONTEIRO et al., 2008), podendo estar diferenciadas ou não.

Numa pesquisa pioneira, iniciada em 1998 e publicada no ano de 2001, BARROS et al. (2001) realizaram a aplicação percutânea de células mononucleares da medula óssea na reparação de falhas experimentais realizadas em rádio de coelhos, obtendo excelentes resultados no processo de reparação óssea em relação ao grupo controle, sobretudo na precocidade de formação do novo tecido.

CROVACE et al. (2008), Del CARLO et al. (2007) e DALLARI et al. (2007) também utilizaram a FCMMO autógena em falhas ósseas críticas de modelos experimentais animais visando à precocidade na osteogênese e obtiveram resultados satisfatórios em seus estudos.

YAMASAKI et al. (2008) realizaram o tratamento de pacientes acometidos por osteonecrose bilateral da cabeça femoral, utilizando osteotomia rotacional transtrocantérica acrescida da aplicação autógena da FCMMO associada à hidroxiapatita e concluíram que o tratamento associado à aplicação das células contribuiu positivamente para o processo de reaparação.

Em 1998, BRUDER et al. demonstraram que culturas de MSC derivadas de medula óssea, depositadas sobre plataformas de hidroxiapatita e sobre cerâmica de cálcio, poderiam ser utilizadas no tratamento de defeitos críticos em fêmures de cães. Como resultados de suas pesquisas, constataram rápido desenvolvimento de tecido ósseo ao redor dos implantes e retorno precoce da função do membro. Essa pesquisa encorajou diversos pesquisadores no mundo todo, que, posteriormente à publicação desses resultados, iniciaram pesquisas utilizando as células mesenquimais cultivadas.

A não união óssea também tornou-se alvo de tratamento por MSC. HERNIGOU et al. (2005) trataram pacientes acometidos por não união óssea na diáfise da tíbia utilizando a FCMMO, aplicada por via percutânea no foco da alteração óssea. Foi observada reversão da não união e consolidação óssea em $88 \%$ dos casos, e o sucesso do tratamento era proporcional à concentração celular obtida.

Com o mesmo intuito, ZAMPROGNO (2007) também realizou o tratamento de nãounião utilizando MSC cultivadas e expandidas em laboratório, na dose de $10^{7}$ células $\mathrm{mL}^{-1}$, realizando aplicação única por aplicação percutânea. Observou que a terapia com células-tronco provenientes da medula óssea mostrouse efetiva para a estimulação osteogênica de não união de fraturas, promovendo a união óssea em pacientes que apresentavam um ano ou mais de fratura e diversas cirurgias anteriores fracassadas.
Recentemente, ARGÔLO NETO (2009) e MONTEIRO (2009) utilizaram culturas de MSC marcadas pela proteína fluorescente verde (GFP) em aplicações autógenas in situ, visando ao tratamento de lesões epiteliais de pacientes diabéticos e de lesões ósseas na calota craniana. Os autores demonstraram a contribuição positiva do transplante desse tipo celular na forma indiferenciada, na cicatrização das feridas cutâneas em camundongos diabéticos e na reparação de defeitos ósseos críticos, respectivamente.

Alguns trabalhos também destacam a aplicação alogênica dessas células. HORWITZ et al. (2002) realizaram duas infusões venosas de MSC na dose de $1 \times 10^{6}$ células $\mathrm{kg}^{-1}$ a $5 \times 10^{8}$ células kg-1 , com intervalos de um mês entre as aplicações, objetivando o tratamento de pacientes que sofriam de severas formas de osteogênese imperfeita (OI). Durante os primeiros seis meses de acompanhamento, os autores já puderam observar maior deposição óssea e menor ocorrência de fraturas nesses pacientes. Um inconveniente para a aplicação venosa é a necessidade de grandes quantidades de células por aplicação, visto que muitas se distribuem para locais distantes à lesão principal.

\section{CONCLUSÕES}

A terapia celular com MSC é uma alternativa terapêutica promissora, pois a diferenciação dessas células em tecidos mesodermais e não mesodermais amplia as possibilidades de utilização clínica, tanto em humanos, quanto em animais. Além disso, as recentes descobertas sobre o comportamento imunológico das MSC aumentaram as perspectivas terapêuticas com o uso dessas células pela possibilidade de tratamento alógeno. Contudo, essa possibilidade deve ser considerada com entusiasmo e cautela, visto que os mecanismos moleculares imunomodulatórios utilizados pelas MSC ainda não são totalmente compreendidos, e a biologia das MSC ainda é uma ciência em formação.

\section{AGRADECIMENTOS}

À Coordenação de Aperfeiçoamento de Pessoal de Nível Superior (CAPES), pela concessão de bolsas de estudo ao primeiro e ao segundo autor; e ao Conselho Nacional de Desenvolvimento Científico e Tecnológico (CNPq), pela concessão de bolsa de produtividade ao terceiro autor.

\section{REFERÊNCIAS}

AGGARWAL, S.; PITTENGER, M.F. Human mesenchymal stem cells modulate allogeneic immune cell responses. Blood, v.105, p.1815-1822, 2005. Disponível em: <http:// bloodjournal.hematologylibrary.org/cgi/content/full/105/4/ 
1815> Acesso em: 23 set. 2009. doi: 10.1182/blood-2004-041559.

ALHADLAQ, A.; MAO, J.J. Mesenchymal stem cells: isolation and therapeutics. Stem Cells Development, v.13, p.436448, 2004. Disponível em: <http://www.liebertonline.com/doi/abs/ 10.1089/scd.2004.13.436? cookieSet=1\&journalCode=scd $>$. Acesso em: 23 set. 2009. doi:10.1089/scd.2004.13.436.

ARGÔLO-NETO, N.M. Tratamento de feridas cutâneas experimentais em camundongos (Mus musculus C57BL/ 6) diabéticos com células-tronco mesenquimais aplicadas de forma isolada e associadas ao plasma autólogo rico em plaquetas. 2009. 121f. Tese (Doutorado Medicina veterinária) - Departamento de Veterinária, Universidade Federal de Viçosa, MG.

ARMULIK, A. et al. Endothelial/pericyte interactions. Circulation Research, v.97, p.512-523, 2005. Disponível em: <http://circres.ahajournals.org/cgi/content/full/97/6/512>. Acesso em: 23 set. 2009. doi: 10.1161/01.RES.0000182903.16652.d7.

BARROS, S.V.G. et al. Auto-enxerto percutâneo de medula óssea. II - Reparação de falhas segmentares produzidas no rádio de coelhos. Ciência Rural, v.31, p.627-632, 2001. Disponível em: <http://www.scielo.br/pdf/cr/v31n4/a11v31n4.pdf >. Acesso em: 23 set. 2009 .

BOBIS, S. et al. Mesenchymal stem cells: characteristics and clinical applications. Folia Histochemica et Cytobiological, v.44, p.215-230, 2006.

BRUDER, S.R. et al. Mesenchymal stem cells in osteobiology and applied bone regeneration. Clinical Orthopaedics and Related Research, v.355S, p.S247-S256, 1998.

CAPLAN, A.I. All MSCs are pericytes? Cell Stem Cell, v.3, p.229-230, 2008. Disponível em: <http://www.cell.com/cellstem-cell/abstract/S1934-5909(08)00406-2>. Acesso em: 23 set. 2009. doi:10.1016/j.stem.2008.08.008.

CAPLAN, A.I. Why are MSCs therapeutic? New data: new insight. Journal of Pathology, v.217, p.318-324, 2009. Disponível em: <http://www.ugr.es/ inmuno/Novedades/parolini/ Caplan,_2009.pdf $>$. Acesso em: 23 set. 2009. doi: 10.1002/ path.2469.

COVAS, D.T. Células-tronco mesenquimais. In: ZAGO, M.A.; COVAS, D.T. Células-tronco: a nova fronteira da medicina. São Paulo: Atheneu, 2006. p.35-48.

CORCIONE, A. et al. Human mesenchymal stem cells modulate B-cell functions. Blood, v.107, p.367-372, 2006. Disponível em: <http://bloodjournal.hematologylibrary.org/cgi/reprint/107/ 1/367>. Acesso em: 23 set. 2009. doi: 10.1182.

CROVACE, A. et al. Use of autologous bone marrow mononuclear cells and cultured bone marrow stromal cells in dogs with orthopaedic lesions. Veterinary Research Communications, v.32, suppl.1, p.39-44, 2008.

DALLARI, D. et al. Enhanced tibial osteotomy healing with use of bone grafts supplemented with platelet gel or platelet gel and bone marrow stromal cells. Journal of Bone and Joint surgery of America, v.89, p.2413-2420, 2007. Disponível em: <http://www.ejbjs.org/cgi/content/abstract/89/11/2413>. Acesso em: 23 set. 2009. doi: 10.2106/JBJS.F.01026.
DEANS, R.J.; MOSELEY, A.B. Mesenchymal stem cells: biology and potencial clinical uses. Experimental Hematology, v.28, p.875-884, 2000. Disponível em: <http://www.sciencedirect.com/ science?_ob=ArticleURL\&_udi=B6VP8-4164V5V$1 \&$ \&user $=10 \&$ \&_rdoc $=1 \&$ \&mt $=\&$ \&_orig $=$ search $\&$ _sort $=\mathrm{d} \&$ _docanchor $=\&$ view $=$ c\&_searchStrId $=1022227845 \&$ \& erunOrigin=google\&_acct $=$ C000050221\&_version $=$ $1 \&$ \& u r l V e r s i o n $=0$ \&_u s e r i d $=10 \&$ md5=bdf25e8ebfabeeefbd211d0bf0b0d110>. Acesso em: 23 set. 2009. doi: 10.1016/S0301-472X(00)00482-3.

DEL CARLO, R.J. et al. Integração de aloenxertos ósseos corticais associados ou não a células-tronco da medula óssea, proteína óssea morfogenética (BMP) e autoenxerto esponjoso em cães. Veterinária e Zootecnia, v.14, p.204-215, 2007. Disponível em: <http://www.fmvz.unesp.br/revista/volumes/ vol14_n2/Revista\%20v14n02_2007_66_77.pdf>. Acesso em: 23 set. 2009 .

DEL CARLO, R.J. et al. Avanços no estudo de células-tronco no Brasil e suas implicações. Ceres, v.56, p.446-450, 2009.

Di NICOLA, M. et al. Human bone marrow stromal cells suppress $\mathrm{T}$ lymphocyte proliferation induced by cellular or nonspecific mitogenic stimuli. Blood, v.99, p.3838-3843, 2002. Disponível em: <http://bloodjournal.hematologylibrary.org/cgi/ content/full/99/10/3838>. Acesso em: 23 set. 2009.

FUCHS, E. et al. Socializing with the Neighbors: stem cells and their niche. Cell, v.116, p.769-778, 2004. Disponível em: < h t t p : / / w w w. p u b m ed c e n t r a l. n i h. g o v / articlerender.fcgi?tool=pubmed\&pubmedid $=15035980>$. Acesso em: 23 set. 2009. doi:10.1016/S0092-8674(04)00255-7.

GRONTHOS, S. et al. Molecular and cellular characterisation of highly purified stromal stem cells derived from human bone marrow. Journal of Cell Science, v.116, p.1827-1835, 2003. Disponível em: <http://jcs.biologists.org/cgi/content/abstract/ 116/9/1827>. Acesso em: 23 set. 2009. doi: 10.1242/jcs.00369.

HERNIGOU, P.H. et al. Percutaneous autologous bone marrow grafting for nonunions - Influence of number and concentration of progenitor cells. Journal of Bone and Joint Surgery, v.87, p.430-1437, 2005. Disponível em: <http://www.ejbjs.org/ cgi/content/abstract/87/7/1430>. Acesso em: 23 set. 2009. doi: 10.2106/JBJS.D.02215.

HERZOG, E.L. et al. Plasticity of marrow-derived stem cells. Blood, v.102, p.3483-3493, 2003. Disponível em: <http:// bloodjournal.hematologylibrary.org/cgi/content/full/102/10/ 3483>. Acesso em: 23 set. 2009. doi: 10.1182.

HIRSCHI, K.K.; D'AMORE, P.A. Pericytes in the microvasculature. Cardiovascular Research, v.32, p.687698, 1996.

HORWITZ, E.M. et al. Isolated allogeneic bone marrow-derived mesenchymal cells engraft and stimulate growth in children with osteogenesis imperfecta: implications for cell therapy of bone. Proceedings of the National Academy of Sciences USA, v.99, p.8932-8937, 2002. Disponível em: <http:// www.pnas.org/content/99/13/8932.full.pdf+html>. Acesso em: 23 set. 2009.

HORWITZ, E.M et al. Clarification of the nomenclature for MSC: the international society for cellular therapy position statement. Cytotherapy, v.7, n.5, p.393-395, 2005. 
HUSS, R. Cells from various sources isolation of primary and immortalized CD34- hematopoietic and mesenchymal stem. Stem Cells, v.18, n.1, p.1-9, 2000. Disponível em: <http:// stemcells.alphamedpress.org/cgi/reprint/18/1/1.pdf $>$. Acesso em: 23 set. 2009 .

KOLF, C.M. et al. Mesenchymal stromal cells. Biology of adult mesenchymal stem cells: regulation of niche, self-renewal and differentiation. Arthritis Research \& Therapy, v.9, p.204-213, 2007. Disponível em: <http://arthritisresearch.com/content/9/1/204> Acesso em: 23 set. 2009. doi:10.1186/ar2116.

Le BLANC, K. Immunomodulatory effects of fetal and adult mesenchymal stem cells. Cytotherapy, v. 6, p. 485-489, 2003.

LOJUDICE, F.H. Identificação de genes diferencialmente expressos durante diferenciação de células-tronco progenitoras mesenquimais. 2008. 173f. Tese (Doutorado em Ciências Biológicas, Bioquímica) - Universidade de São Paulo, SP.

MAJUMDAR, M.K. et al. Characterization and functionality of cell surface molecules on human mesenchymal stem cells. Journal of Biomedical Science, v.10, p.228-241, 2003. Disponível em: <http://content.karger.com/ProdukteDB/ produkte.asp?Doi=68710>. Acesso em: 23 set. 2009. doi: $10.1159 / 000068710$

MAMBELLI, L.I. et al. Characterization of equine adipose tissue-derived progenitor cells before and after cryopreservation. Tissue Engineering, v.15, n.1, p.87-94, 1999.

MARTIN, P. Wound healing - aiming for perfect skin regeneration. Science, v.276, p.75-81, 1997. Disponível em: <http://www.sciencemag.org/cgi/content/abstract/276/5309/75> Acesso em: 23 set. 2009. doi: 10.1126/science.276.5309.75.

MEIRELLES, L.S. et al. Mesenchymal stem cells reside in virtually all post-natal organs and tissues. Journal of Cell Science, v.119, p.2204-2213, 2006. Disponível em: <http:// jcs.biologists.org/cgi/reprint/119/11/2204.pdf>. Acesso em: 23 set. 2009. doi: 10.1242/jcs.02932.

MEIRELLES, L.S. et al. In search of the in vivo identity of mesenchymal stem cells. Stem Cells, v.26, p.2287-2299, 2008. Disponível em: <http://stemcells.alphamedpress.org/cgi/ content/abstract/2007-1122v1>. Acesso em: 23 set. 2009. doi:10.1634/stemcells.2007-1122.

MENDELOW B.D. et al. Characterization of bone marrow stromal cells in suspension and monolayer cultures. British Journal of Haematology, v.46, p.15-22, 1980. Disponível em: <http://www3.interscience.wiley.com/cgi-bin/fulltext/ 120729704/PDFSTART>. Acesso em: 23 set. 2009. doi: 10.1111/j.1365-2141.1980.00015.x.

MINGUELL, J.J. et al. Biology and clinical utilization of mesenchymal progenitor cells. Brazilian Journal of Medical and Biological Research, v.33, n.8, p.881-887, 2000. Disponível em: http://www.scielo.br/scielo.php?pid=S0100 879X2000000800003\&script=sci_arttext. Acesso em: 23 set. 2009. doi: 10.1590/S0100-879X2000000800003.
MONTEIRO, B.S. et al. Terapia celular em reparação óssea aplicação clínica de células-tronco mesenquimais. Ciência Veterinária nos Trópicos, v.11, s2, p. 95-100, 2008. Disponível em: <http://www.veterinaria-nos-tropicos.org.br/ palestras/p95.pdf>. Acesso em: 23 set. 2009.

MONTEIRO, B.S. Tratamento de defeitos críticos em calvária de camundongos com células-tronco mesenquimais associadas ou não ao plasma rico em plaquetas. 2009. 109f. Tese (Doutorado Medicina Veterinária) - Departamento de Veterinária, Universidade Federal de Viçosa, MG.

MORRISON, S.J. et al. Stem cells and niches: mechanisms that promote stem cell maintenance throught life. Cell, v.132, p.598-611, 2008. Disponível em: <http://www.cell.com/ abstract/S0092-8674(08)00139-6>. Acesso em: 23 set. 2009. doi: 10.1016/j.cell.2008.01.038.

NAUTA, A.J.; FIBBE, W.E. Immunomodulatory properties of mesenchymal stroma cells. Blood, v.110, n.10, p.3499-3506, 2007. Disponível em: <http://bloodjournal.hematologylibrary.org/ cgi/content/abstract/110/10/3499>. Acesso em: 23 set. 2009. doi: 10.1182/blood-2007-02-069716.

NARDI, N.B; MEIRELLES, L.S. Mesenchymal stem cells: isolation, in vitro expansion and characterization. Handbook of Experimental Pharmacology, v.174, p.249-282, 2006

PATEL, S.A. et al. Immunological properties of mesenchymal stem cells and clinical implications. Archivum Immunologiae et Therapiae Experimentalis, v.56, n.1, p.1-8, 2008. Disponível em: <http://www.labmeeting.com/paper/9582298/ patel-immunological-properties-of-mesenchymal-stem-cellsand-clinical-implications $>$. Acesso em: 23 set. 2009. doi: 10.1007/s00005-008-0001-x.

PHINNEY, D.G.; PROCKOP, D.J. Concise review: mesenchymal stem/multipotent stromal cells: the state of transdifferentiation and modes of tissue repair - current views. Stem Cells, v.25, p.2896-2902, 2007. Disponível em: <http:/ /www3.interscience.wiley.com/journal/121586794/abstract $>$. Acesso em: 23 set. 2009. doi:10.1634/stemcells.2007-0637.

PITTENGER, M.F. et al. Multilineage potential of adult human mesenchymal stem cells. Science, v.284, p.143-147, 1999. Disponível em: <http://www.sciencemag.org/cgi/content/ abstract/284/5411/143>. Acesso em: 23 set. 2009. doi: 10.1126/science.284.5411.143.

SOTIROPOULOU, P.A. et al. Reciprocal Interactions between human mesenchymal stem cells and natural killer cells. Stem Cells, v.24, n.1, p.74-85, 2006. Disponível em: <http:// stemcells.alphamedpress.org/cgi/content/abstract/27/3/693>. Acesso em: 23 set. 2009. doi:10.1634/stemcells.2004-0359.

TAKAHASHI, K. et al. Induction of pluripotent stem cells from adult human fibroblasts by defined factors. Cell, v.131, p.1-12, 2007. Disponível em: < http://www.sciencedirect.com/ science? ob=ArticleURL\&_udi=B6WSN-4R70J0T18 _user $=10 \& \_r d o c=1 \&$ fmt $=\&$ \& orig $=$ search \&_sort $=$ d\&_docanch or $=\&$ vie w $=$ c \&_a c ct $=$ C $000050221 \&$ \&_version $=1 \&$ \& u rlVersion=0\&_userid=10\&md5=03bdc1f7799e5b3cb7a9be60d5b18bb3 $>$. Acesso em: 23 set. 2009. doi: 10.1016/j.cell.2007.11.019. 
TSIROGIANNI, A.K. et al. Wound healing: immunological aspects. Injury, v.375, p.S5-S12, 2006. Disponível em: <http:/ $/ \mathrm{w} w \mathrm{w}$. s c i e $\mathrm{n}$ c e d i r e c t. c o m/ science?_ob=ArticleURL\&_udi=B6T78-4JRKWNJ$18 \_$_user $=10$ \&_rdoc $=18$ fmt $=$ \&_orig $=$ search\&_sort $=\mathrm{d}$ \&_docan chor $=\&$ view $=$ c \&_searchStrId=1025165136\&_re runOrigin=google\&_acct $=\mathrm{C} 000050221 \&$ _versio $\mathrm{n}=1 \&$ _ u r l Versio n $=0 \&$ _ u se rid $=10 \& \mathrm{~m}$ d5=ea01647b202769f1c9a992d7c5a88eb2>. Acesso em: 23 set. 2009. doi:10.1016/j.injury.2006.02.035.

VERFAILLIE, C.M. Adult stem cells: assessing the case for pluripotency. Trends in Cell Biology, v.12, p.502-508, 2002. Disponível em: <http://www.cell.com/trends/cell-biology/ abstract/S0962-8924(02)02386-3>. Acesso em: 23 set. 2009. doi:10.1016/S0962-8924(02)02386-3.

WAN, C.D et al. Immunomodulatory effects of mesenchymal stem cells derived from adipose tissues in a rat orthotopic liver transplantation model. Hepatobiliary \& Pancreatic
Diseases International, v.7, p.29-33, 2008. Disponível em: < h t t p : / / w w w. hbpdint.com/upload/P D F/ 200813193933152316.pdf>. Acesso em: 23 set. 2009.

ZAMPROGNO, H. Células tronco esqueléticas para o tratamento de não união de fraturas. Acta Scientiae Veterinariae, v.35, s2, p.s289-s290, 2007. Disponível em: $<$ ht t : / / www.ufrgs.br/actavet/ 35 - suple-2/27\%20ANCLIVEPA.pdf>. Acesso em: 23 set. 2009.

ZUCCONI, E. et al. Mesenchymal stem cells derived from canine umbilical cord vein - a novel source for cell therapy studies. Stem Cells and Development, in proof, p.1-33, 2009. Disponível em: <http://www.liebertonline.com/doi/abs/ 10.1089/scd.2008.0314>. Acesso em: 23 set. 2009. doi: $10.1089 /$ scd.2008.0314

YAMASAKI, T. et al. Transplantation of bone marrow mononuclear cells enables simultaneous treatment with osteotomy for osteonecrosis of the bilateral femoral head. Medical Science Monitor, v.14, p.CS23-CS30, 2008. 